\title{
The Combination of Hydrogen and Oxygen with on Palladium-Silver Alloys*
}

\author{
Masamichi KowAKA \\ (The Inst. Sci. \& Ind. Research, Osaka University) \\ (Received June 11, 1959)
}

\section{Synopsis}

Kinetic measurements of the combination of hydrogen and oxygen on palladium, silver, and their alloys have been made in the temperature range of $80^{\circ} \mathrm{C}$ and $450^{\circ} \mathrm{C}$. Ribbon form samples were used. The change in pressure was measured at a constant volume by an automatic controlling system. It was found that the pretreatment by oxygen raises the reaction rate for palladium, but the effect is not considerable for silver. The apparent activation energy of the reaction remains constant and begins to increase at 60 at $\%$ silver with increasing silver content. The activity of a series of alloys rises to a small maximum at about 30 at $\%$ silver content. The results are discussed.

\section{Introduction}

The union of hydrogen and oxygen on the metal surfaces is the one of the typical heterogeneous reactions, but few studies have been reported on this reaction on alloy catalysts. It has been shown that the rate of reaction is of an order between zero and the first with respect to hydrogen and zero or negative with respect to oxygen ${ }^{(1)}$. The results obtained are not unique, even under controlled conditions. The activities of metals are generally variable.

The mechanism of catalytic reaction of the combination of hydrogen and oxygen by palladium is mainly one of alternate oxidation of the metal and reduction of its oxide ${ }^{(2)}$. Silver is well known to be an active oxidation catalyst while palladium is not. On the other hand, palladium is a good reduction catalyst and silver is not. These metals are mixible in the whole range and the lattice parameter increases almost linearly from 3.884 $\AA$ for palladium to $4.077 \AA$ for silver.

The object of this work is to obtain informations on the alloy catalysts of a heterogeneous reaction. In order to find the role of the band structure of the alloys on the combination reaction, a series of palladium-silver alloys was chosen as catalyst.

\section{Experimental}

Palladium, silver, and their alloys used were in the form of ribbons, $500 \mathrm{~mm}$ long, $2.0 \mathrm{~mm}$ wide, and $0.11 \mathrm{~mm}$ thickness. The catalysts were annealed at $800^{\circ} \mathrm{C}$ for 2 hours in vacuo and introduced in the reaction vessel of the capacity of $17.2 \mathrm{~mL}$. The system was evacuated and the catalyst in the vessel was heated at $400^{\circ} \mathrm{C}$ for 1 minute in hydrogen of a few $\mathrm{cm} \mathrm{Hg}$ followed by pumping out of the hydrogen for more than 1 hour at the same temperature. The vessel was then cooled down to a desired temperature, the gas mixture of hydrogen and oxygen $(2: 1)$ was introduced, and the reaction took place. The same treatments were carried out just before every run. The results obtained are reproducible by these treatments.

The pressure decreases as the reaction takes place. The change in pressure in the system was measured at a constant volume by an automatic controlling system $^{(3)}$.

The hydrogen used was prepared by electrolysis of $0.2 \mathrm{~N}$ sodium hydroxide. The gas was kept in a reservior after passing a Pd-asbestos, calcium chloride, phosphorous pentoxide, and solid carbon dioxide-alcohol trap.

Oxygen was also obtained from the anode in the same electrolysis, and was purified by passing through a solid carbon dioxide-alcohol trap followed by activated charcoal

* This paper was read at the general meeting of Japan Institute of Metals held at Tokyo on April 3,1959 .

(1) P.H.Emmett: Catalysis, Vol. 1, Reinhold Pub. Co. (1954),160.

(2) D.J.Chapman, G.Gregory: Proc. Roy. Soc. A, 147(1934), 68.

(3) M.Kowaka: J.Japan Inst. Metals, 23(1959),655. 
cooled at $-78^{\circ} \mathrm{C}$.

\section{Results}

The gas mixture of hydrogen and oxygen $(2: 1)$ of about $16 \mathrm{~cm} \mathrm{Hg}$ was admitted into the reaction vessel in which the palladium catalyst was introduced. The change in total

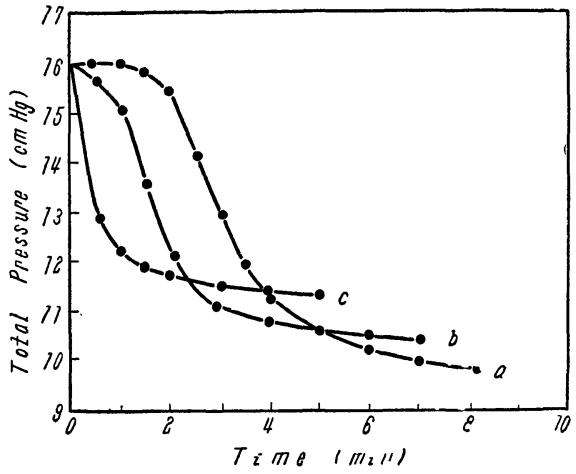

Fig. 1 Union of hydrogen and oxygen on palladium. Variation of total pressure with time of reaction in minutes at $100^{\circ}$.

a : Clean palladium.

b: Palladium pretreated by hydrogen.

c: Palladium pretreated by oxygen pressure with time at $100^{\circ}$ is shown in Fig. 1. Curve $a$ shows the result of the reaction on the clean palladium surface. There is no reaction at the start followed by a rapid decrease in pressure and then the reaction is completed. After the palladium catalyst was exposed to hydrogen of $15 \mathrm{~cm} \mathrm{Hg}$ for $5 \mathrm{minu}-$ tes (accompanying a decrease in pressure of $2.1 \mathrm{~cm} \mathrm{Hg}$ ), the remainder of the hydrogen gas was quickly pumped out, and the gas mixture of hydrogen and oxygen was immediately introduced, curve $b$ was obtained. The catalyst was treated by oxygen instead of hydrogen, i.e. it was exposed to oxygen of $13 \mathrm{~cm} \mathrm{Hg}$ for 17 minutes(no pressure change was observed), and the gas mixture was admitted after pumping out the residual oxygen gas. Curve $c$ was obtained. There is no induction period, the reaction takes place rapidly at the start and is completed.

Fig. 2 shows the combination of hydrogen and oxygen over silver at $400^{\circ}$. Curves $a$, $b$, and $c$ have the same meanings as above. The pressure decreases almost linearly with time differing from a pure palladium.

One of a series of experiments on the Pd-Ag alloys is shown in Fig. 3. This is the combination of hydrogen and oxygen over 30 at $\% \mathrm{Ag}-\mathrm{Pd}$ alloy at $80^{\circ}, 100^{\circ}$, and $130^{\circ}$. The reaction takes place after a short induction period. The decrease in pressure against time is almost linear.

When the rate of decrease in pressure against temperature was measured, the apparent activation energy of the reaction can be obtained by the Arrhenius equation, i.e.

$$
k=B \exp (-E / R T) \text {, }
$$

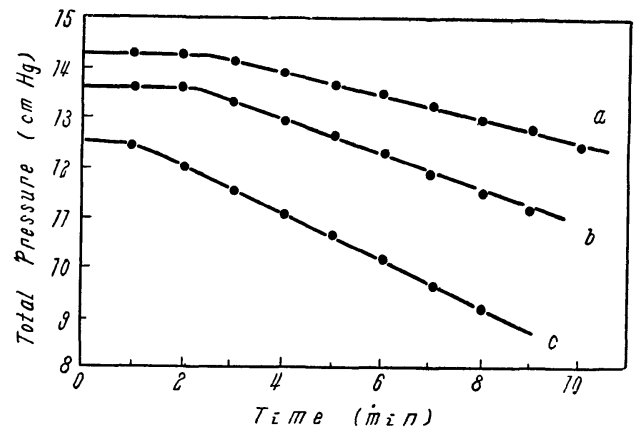

Fig. 2 Union of hydrogen and oxygen on silver.

Variation of total pressure with time of reaction in minutes at $400^{\circ}$.

a: Clean silver.

b: Silver pretreated by hydrogen.

c: Silver pretreated by oxygen.

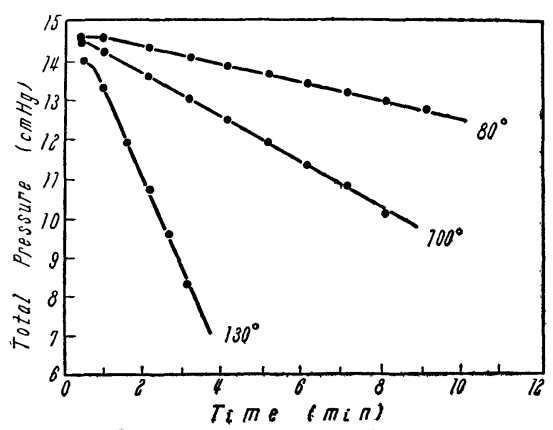

Fig. 3 Union of hydrogen and oxygen on 30 at \% Ag-Pd alloy at $80^{\circ}, 100^{\circ}$ and $130^{\circ}$. Variation of total pressure with time in minutes.

where $k$ the rate constant, $E$ the apparent activation energy, $R$ the gas constant, $B$ the constant independent of temperature, and $T$ the absolute temperature.

The rate constants for a series of the alloys are plotted against the reciprocal of absolute temperatures in Fig.4. From Fig.4, the apparent activation energy as a function of alloy compositions is shown in Fig.5 (full line). The activation energy remains constant 
and begins to rise at 60 at $\% \mathrm{Ag}-\mathrm{Pd}$ alloy. This is the critical composition of the alloys. The activation energy for pure palladium was not obtained because of the complexity of

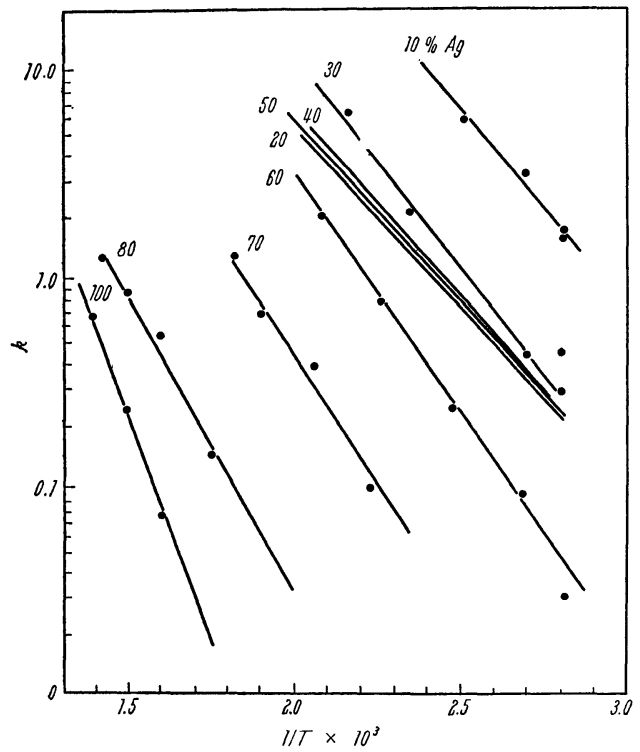

Fig.4 Variation of rate cunstant for a series of $\mathrm{Ag}-\mathrm{Pd}$ alloys with reciprocal of absolute temperature.

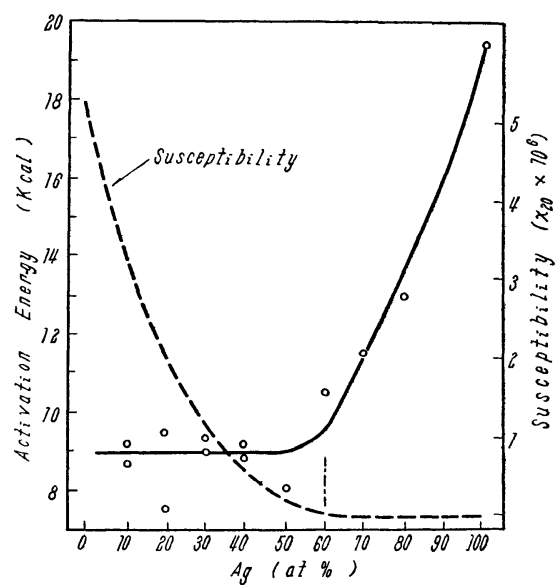

Fig.5 Activation energy for the union of hydrogen and oxygen for a series of Ag-Pd alloys. Dashed line denotes the paramagnetic susceptibility after Hoare et $\mathrm{al}^{(4)}$.

the behavior. The paramagnetic susceptibility is shown in the same figure(dashed line) ${ }^{(4)}$. The susceptibility decreases contineously with increasing silver content until at 60 at $\%$ where the holes in the $d$-band in palladium are filled by silver.

Fig. 6 shows the variation of activity with composition of the alloys at $100^{\circ}$. The rate of reaction, $d p / d t$, is plotted against silver content. The activity rises to a small maximum at about 30 at $\% \mathrm{Ag}-\mathrm{Pd}$ alloy. It decreases contineously after that composition and reduces to zero at 70 at $\% \mathrm{Ag}-\mathrm{Pd}$ alloy. If we choose the activities at higher temperatures, this curve may shift upward. The surface areas of the alloys were not measured. They were assumed to be the same. The apparent surface area was $21 \mathrm{~cm}^{2}$.

\section{Discussion}

The union of hydrogen and oxygen on palladium, silver and their alloys have been studied. Let us consider on pure metals first. For palladium it has an induction period at the start, but no induction period appeared for the catalyst pretreated by oxygen. For

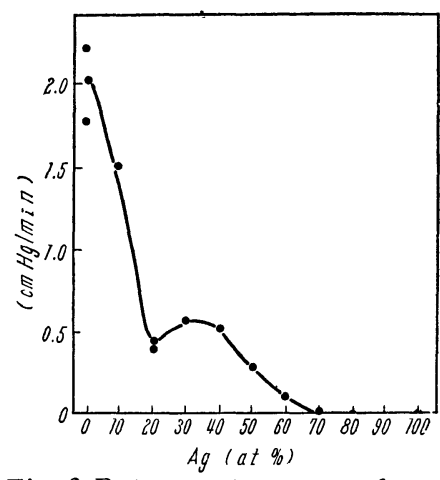

Fig. 6 Rate constant as a function of composition of silver at $100^{\circ}$. silver, the pressure of gases decreases almost linearly with time and the effect of oxygen pretreatmet is not considerable. It is suggested that the difference in reaction on palladium and on silver may be caused by the different ability of these metals for oxygen and hydro-

Table 1 Heats of formation of bulk and surface oxides for palladium and silver ( $\mathrm{kcal} / \mathrm{mol})$ after Bortner \& Parravano(5).

\begin{tabular}{c|c|c}
\hline & bulk $\left(298^{\circ} \mathrm{K}\right)$ & $\operatorname{surface}\left(500^{\circ} \mathrm{K}\right)$ \\
\hline $\mathrm{PdO}$ & -21.9 & -24.6 \\
\hline $\mathrm{AgO}$ & -7.3 & -54.0 \\
\hline
\end{tabular}

gen. There is a considerable difference in heats of chemisorption of oxygen on palladium and on silver. The heats of formation of bulk and surface oxides for these two metals 
are listed in Table $1^{(5)}$. In the case of bulk $\mathrm{Pd}-\mathrm{O}$ is more stable than $\mathrm{Ag}-\mathrm{O}$, but the surface Ag-O is more stable than the surface $\mathrm{Pd}-\mathrm{O}$. Chemisorbed oxygen on palladium can be removed easily by hydrogen but oxygen on silver is not.

As shown in Fig.5, the paramagnetic susceptibility of the alloys decreases contineously and reduces to zero at 60 at $\% \mathrm{Ag}-\mathrm{Pd}$ alloy, while the activation energy for the reaction remains constant until the same composition of the alloys and begins to increase with increasing silver content. It was found that no parallelism can be found between the surface and the bulk properties, except that the abrupt change occured at the critical composition of the alloys ( 60 at $\% \mathrm{Ag}-\mathrm{Pd}$ ). This composition of alloy is what the holes in the $d$-band are filled by silver. This shows that the sorption of hydrogen plays an important role on the reaction over the alloy catalysts. Because it is generally believed that oxygen chemisorption on metals does not involve direct participation of $d$-electrons.

Finally, the curve of a change in activity of a series of alloys has a maximum at the concentration of 30 at $\% \mathrm{Ag}-\mathrm{Pd}$ alloy. The catalytic activities do not vary contineously with composition of silver as would be expected from the band theory of metals. The activities should decrease contineously with increasing silver content. The cause of the anomalous behavior at 30 at \% silver is not clear but may be interpreted by taking consideration of the variation of frequency factor, $B$, in the Arrhenius equation by alloying with silver. Many physical properties rises to a maximum(or minimum) at this composition*. Such a behavior has recently been found on the hydrogenation of benzene over Ni$\mathrm{Cu}$ alloys ${ }^{(6)}$, but there is no slender explanation. Further studies are needed in order to make sure the above discussion.

\section{Conclusions}

The following informations on the combination of hydrogen and oxygen over palladiumsilver alloys are obtained:

(1) For pure palladium, there is an induction period at the start followed by a rapid decrease in pressure.

(2) For silver, the decrease in pressure is a linear function of time and the effect of the pretreatment is not considerable.

(3) The activation energy of the reaction remains constant and begins to rise at 60 at $\%$ $\mathrm{Ag}-\mathrm{Pd}$ alloy.

(4) The small maximum activity is found at about 30 at $\% \mathrm{Ag}-\mathrm{Pd}$ alloy.

(5) M.H.Bortner, G.Parravano: Adv. in Catalysis, IX(1957), 424.

(6) W.K.Ha11, P.H.Emmett: J.Phys. Chem., 62(1958), 817.

* Maximum electric resistivity, mechanical hardness, solubility of hydrogen, and minimum coefficient of thermal expansion. 